Special issue of the International Conference on Computational and Experimental Science and Engineering (ICCESEN 2014)

\title{
Investigation of Radiation Absorption Properties of Some India Granites
}

\author{
B. $\mathrm{MAVI}^{a, *}$ AND I. AKKURT ${ }^{b}$ \\ ${ }^{a}$ Physics Department, Amasya University, Amasya, Turkey \\ ${ }^{b}$ Physics Department, Süleyman Demirel University, Isparta, Turkey
}

\begin{abstract}
The radiation shielding properties of India granites have been investigated. Gamma-ray attenuation coefficients of some India granites were determined for different energies, 662, 1173, and $1332 \mathrm{keV}$. The results were compared with the calculation of XCOM at the photon energy of 1-10 GeV. Good agreement between experimental and theoretical results has been observed.
\end{abstract}

DOI: 10.12693/APhysPolA.128.B-370

PACS: 07.85.-m, 78.20.Ci

\section{Introduction}

Besides the beneficial effects the radiation used in medicine-industry also have harmful effects. Radiation protection has become important to get rid of these harmful effects. Shielding is the most important way to against radiation protection. There are several different materials to be used as shielding material [1-6].

For this purposes, in this study, radiation absorption properties of some India granite samples (Crema Porrino, Kristal Yellow, Tan Brown, New Imperial Red) have been measured and calculated.

\section{Material and methods}

\subsection{Experimental methods}

In this study the linear attenuation coefficients $\mu$ for India granite samples were measured at the photon energies of 662 and 1173, $1332 \mathrm{keV}$ obtained from ${ }^{137} \mathrm{Cs}$ and ${ }^{60} \mathrm{Co} \gamma$-ray sources, respectively.

The detection of $\gamma$-rays has been performed using a gamma spectrometer, contains a Canberra type $3^{\prime \prime} \times 3^{\prime \prime}$ $\mathrm{NaI}(\mathrm{Tl})$ detector which is connected to the 16384 channels multi channel analyser (MCA). The communication of the system was performed using Genie2000 software [7].

\subsection{Theoretical basis}

The linear attenuation coefficients (1) can be extracted by Lambert law:

$$
\mu=\frac{1}{x} \ln \left(\frac{N_{0}}{N}\right),
$$

where $\mu$ is the linear attenuation coefficient; $x$ is the thickness of the sample $[\mathrm{cm}], N_{0}$ is the number of counts recorded in the detector before attenuation; $N$ is the number of counts recorded in the detector after attenuation.

*corresponding author; e-mail: fbmavi32@hotmail.com
With the known density $\rho$ of a material, the mass attenuation coefficients $\mu / \rho$ were obtained via measuring the linear attenuation coefficients $\mu$. The theoretical $\mu / \rho$ values for the granite samples were obtained by XCOM program which uses chemical parameters of a mixture material providing total cross sections as well as partial cross sections for various interaction processes and the database at photon energy of $1 \mathrm{keV}$ to $100 \mathrm{GeV}[8,9]$.

The effectiveness of gamma-ray shielding is described in terms of the half value layer $(H V L)$ or the tenth value layer $(T V L)$ of a material. $H V L$ is the thickness of an absorber that will reduce the radiation to half, and the $T V L$ is the thickness of an absorber that will reduce the gamma radiation ten times of its initial intensity. $H V L$ and $T V L$, the linear attenuation coefficients were concluded using the following equations (4):

$$
T V L=\frac{\ln 10}{\mu}, \quad H V L=\frac{\ln 2}{\mu},
$$

where $\mu$ is the linear attenuation coefficient $\mu\left[\mathrm{cm}^{-1}\right]$.

\section{Results and discussion}

The measured linear attenuation coefficient $(\mu)$ for different granite samples have been obtained for 662, 1173 and $1332 \mathrm{keV}$ gamma rays and the results have been displayed in Fig. 1.

It can be seen from Fig. 1. that the measured linear attenuation coefficients decreased with the increasing gamma ray energy for samples. Over $75 \%$ correlation have been found for all samples. It can be seen that the highest value obtained for Tan Brown at $662 \mathrm{keV}$ and New Emperial Red at 1173-1332 keV.

The linear attenuation coefficients $(\mu)$ for India granites were measured at photon energies of 662, 1173 and $1332 \mathrm{keV}$ and calculated at photon energies of $1 \mathrm{keV}-$ $100 \mathrm{GeV}$. The measured results were also compared with the calculated results obtained by XCOM and displayed in Fig. 2.

Figure 3 show that transmission rate of the granite as a function of material thickness. It can be seen from this figure that larger thickness of materials is needed to stop higher energy photons. 

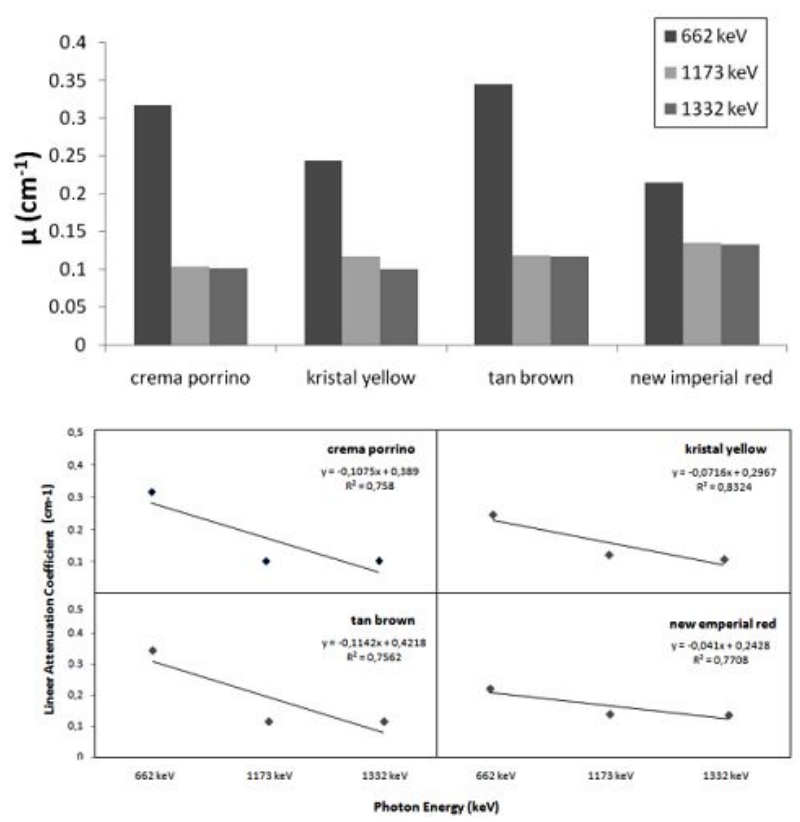

Fig. 1. The measured linear attenuation coefficients correlation with according to the photon energy for India granite samples.

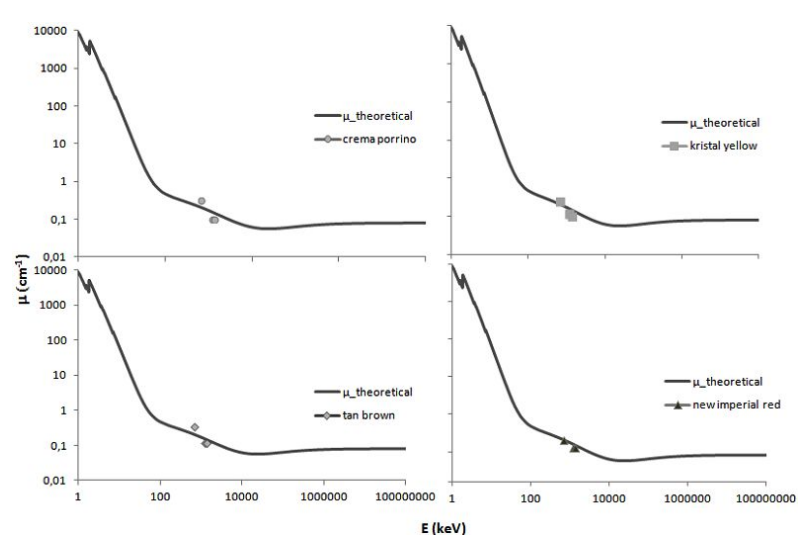

Fig. 2. The linear attenuation coefficient of India granite samples as a function of photon energies.

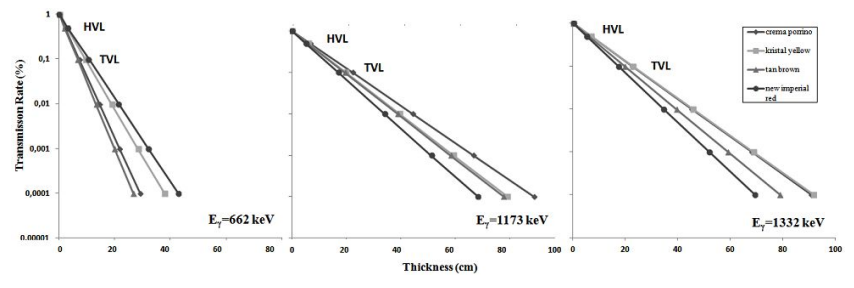

Fig. 3. Transmission rate of the granite for ${ }^{137} \mathrm{Cs}$ and ${ }^{60} \mathrm{Co}$.

\section{Conclusions}

Granites are commonly used construction material. The India granite samples gamma-ray shielding properties have been studied theoretically and experimentally at different energies. It was observed that in terms of radiation shielding the Tan Brown and New Emperial Red India granite samples were more suitable than other tested samples.

\section{References}

[1] J.H. Hubbell, Int. J. Appl. Radiat. Isot. 33, 1269 (1982).

[2] I. Akkurt, H. Akyıldırım, F. Karipcin, B. Mavi, J. Saudi Chem. Soc. 16, 199 (2012).

[3] I. Akkurt, H. Akyıldırım, B. Mavi, Ş. Kilinçarslan, C. Başyiğit, Acta Phys. Pol. A 121, 138 (2012).

[4] M.I. Awadallah, M.M.A. Imran, J. Environ. Radioactiv. 94, 129 (2007).

[5] B. Mavi, Ann. Nucl. Energy 44, 22 (2012).

[6] H. Baltas, U. Cevik, E. Tirasoglu, B. Ertugral, G. Apaydın, A.I. Kobya, Radiat. Meas. 39, 33 (2005).

[7] Genie 2000 (3.0), Operation Manual, Canberra Industries, 2004.

[8] M.J. Berger, J.H. Hubbell, XCOM photon cross sections on a personal computer, NBSIR 87-3597, National Bureau of Standards, Gaithersburg 1987.

[9] I. Akkurt, Ann. Nucl. Energy 36, 1702 (2009). 